\title{
Supraclavicular Lymph Node Biopsy
}

National Cancer Institute

\section{Source}

National Cancer Institute. Supraclavicular Lymph Node Biopsy. NCI Thesaurus. Code C137935.

Removal or sampling of lymph nodes in the supraclavicular area. 